\title{
CONSULTÓRIO NA RUA: PERCEPÇÕES DE PESSOAS ATENDIDAS PELA EQUIPE MULTIPROFISSIONAL
}

\section{OFFICE ON THE STREET: PERCEPTIONS OF PEOPLE ATTENDED BY THE MULTIDISCIPLINARY TEAM}

\author{
Floriacy Stabnow Santos $^{1}$ Kelli Carvalho de Oliveira ${ }^{2}$ Elisangela Viana Brito ${ }^{3}$ Laise Sousa $^{2}$ \\ Siqueira ${ }^{4}$ Livia Maia Pascoal ${ }^{5}$ Jacks Soratto $^{6}$ Marcelino Santos Neto $^{7}$
}

\begin{abstract}
RESUMO
Objetivo: Conhecer as percepções e sobre o atendimento oferecido pela equipe multiprofissional aos usuários atendidos pelo programa Consultório na Rua. Métodos: Pesquisa exploratória descritiva com abordagem qualitativa, realizada no período de janeiro a maio de 2019 em Imperatriz-MA. A população abrangida pelo estudo foram os pacientes atendidos, abordados durante os atendimentos pela equipe multiprofissional, com amostra final de 16 pacientes. Os dados foram coletados através de entrevista semiestruturada e analisados empregando o método de análise de conteúdo temática, subsidiada pelo software Atlas.ti. Resultados: Os resultados do estudo foram estruturados em três categorias: Acesso ao serviço; Acolhimento e satisfação dos usuários; e Expectativas frente aos serviços ofertados. O compromisso da equipe e os entraves administrativos foram mencionados, assim como o acolhimento presente, fator que fortalece o vínculo entre equipe/paciente. Conclusão: Concluiu-se que os sujeitos do estudo apresentaram-se satisfeitos com os atendimentos realizados avaliando a estratégia do programa de forma positiva, mas queixaram-se da falta de continuidade e periodicidade da assistência que receberam.
\end{abstract}

Palavras chave: Vulnerabilidade; Atenção Integral à Saúde; Equipe de Assistência ao Paciente; População em Situação de Rua.

\begin{abstract}
Objective: To know the perceptions and about the service offered by the multidisciplinary team to the users assisted by the Office in the Street program. Methods: Descriptive exploratory research with a qualitative approach, conducted from January to May 2019 in Imperatriz-MA. The population covered by the study were the patients treated, addressed during the visits by the multidisciplinary team, with a final sample of 16 patients. Data were collected through semi-structured interviews and analyzed using the thematic content analysis method, subsidized by Atlas.ti software. Results: The results of the study were structured into three categories: Access to the service; Reception and satisfaction of users; and Expectations in the face of the services offered. The commitment of the team and administrative obstacles were mentioned, as well as the present reception, a factor that strengthens the bond between team/patient. Conclusion: It was concluded that the study subjects were satisfied with the care performed by evaluating the program strategy in a positional way, but complained about the lack of continuity and periodicity of the care they received.

Keywords: Vulnerability; Comprehensive Health Care; Patient Care Team; Community Health Homeless Persons.
\end{abstract}

\footnotetext{
${ }^{1}$ Enfermeira, Doutora em Ciências. Professora Adjunta da Universidade Federal do Maranhão (UFMA) no Curso de Graduação em Enfermagem, na Pós-graduação em Saúde e Tecnologia (PPGST). Orcid: http://orcid.org/0000-0001-78407642floriacys@gmail.com

2 Possui graduação em enfermagem pela Universidade Federal do Maranhão. Orcid https://orcid.org/0000-0003-1874-6698 Email:kelliufma@hotmail.com

3 Possui graduação em enfermagem pela Universidade Federal do Maranhão. Orcid https://orcid.org/0000-0003-3226-9998 Email: lisaufma@ hotmail.com

${ }^{4}$ Enfermeira, Especialista em Saúde da Família. Discente do Programa de Pós-graduação em Saúde e Tecnologia da Universidade Federal do Maranhão. Orcid https://orcid.org/0000-0003-1224-7601 Email:laisesousasiqueira@gmail.com

${ }^{5}$ Enfermeira, Doutora em Enfermagem, Professora Adjunta da Universidade Federal do Maranhão (UFMA) no Curso de Graduação em Enfermagem, na Pós Graduação em Saúde e Tecnologia (PPGST) e Enfermagem (PPGENF). Orcid: https://orcid.org/0000-00030876-3996 Email: livia_mp@ hotmail.com

${ }^{6}$ Enfermeiro, Doutor em Enfermagem. Professor Adjunto da Universidade do Extremo Sul Catarinense no curso de Graduação em em enfermagem, medicina, residência multiprofissional em atenção básica/saúde da família, saúde coletiva e do Programa de Pósgraduação em Saúde Coletiva [mestrado profissional. Orcid https://orcid.org/0000-0001-5154-1542 Email:jacks@unesc.net

${ }^{7}$ Farmacêutico Bioquímico, Doutor em Ciências. Professor Adjunto da Universidade Federal do Maranhão (UFMA) no Curso de Graduação em Enfermagem, na Pós-graduação em Saúde e Tecnologia (PPGST) e na Pós-graduação em Enfermagem (PPGENF). Orcid: https://orcid.org/0000-0002-6105-1886 Email: marcelinosn@ gmail.com
} 


\section{INTRODUÇÃO}

O Consultório na Rua (CnaR), é um programa de atenção a saúde formado por equipes multiprofissionais que prestam atenção integral à saúde de populações vulneráveis do ponto de vista socioenômica, instituído em 2011 pela Política Nacional de Atenção Básica (PNAB) do Sistema Único de Saúde (SUS) com objetivo de atuar frente aos diferentes problemas e necessidades de saúde da população em situação de rua, inclusive na busca ativa e cuidado aos usuários de álcool, crack e outras drogas ${ }^{(1)}$.

Ressalta-se que a realidade vivenciada por pessoas atendidos pelo CnaR é bem diferente da maioria da população, visto que a marginalização os torna socialmente excluídos e diferentes grupos de pessoas como imigrantes, desempregados, moradores de rua, egressos dos sistemas penitenciário e psiquiátrico, desprovidos de fortes vínculos afetivos, usuários de substâncias psicoativas, entre outros, compõem essa população ${ }^{(2)}$. Destaca-se ainda a existência dos chamados "trecheiros", pessoas que transitam de uma cidade a outra, caminhando pelas estradas a pé, de carona ou se valendo de passagens cedidas por entidades assistenciais ${ }^{(3)}$.

Este público tão heterogêneo tem em comum a pobreza, vínculos familiares rompidos, vivência de um processo de desfiliação social pela ausência de trabalho assalariado e das proteções derivadas ou dependentes dessa forma de trabalho, sem moradia convencional regular, tendo a rua como o espaço de moradia e sustento ${ }^{(4)}$.

Considerando tais características, o CnaR lida com diferentes problemas e necessidades desta população, desenvolvendo ações compartilhadas e integradas com as equipes da Estratégia Saúde da Família (ESF), dos Centros de Atenção Psicossocial (CAPS), dos serviços de urgência e emergência e de outros pontos de atenção, de acordo com a necessidade do usuário ${ }^{1}$. Para atender tal demanda, se faz necessário que as ações ofertadas pela equipe de saúde sejam norteadas pelos princípios e diretrizes do SUS, uma vez que estas propõem uma clínica ampliada, dentro de uma ética de cuidado integral, focada na promoção da saúde ${ }^{(5)}$.

A Portaria do Ministério da Saúde $N^{\circ}$ 122, de 25 de janeiro de $2011^{(1)}$, define as diretrizes de organização e funcionamento das equipes do $\mathrm{CnaR}$, esclarece a atuação dos profissionais da saúde que compõe a equipe multiprofissional, tais como Enfermeiro, Psicólogo, Assistente Social, Terapeuta Ocupacional, Médico, Agente Social, Técnico ou Auxiliar de Enfermagem e Técnico em saúde bucal, e deixa explícito que a equipe trabalha com pacientes em condição desfavoráveis, e que devem prestar assistência onde eles se encontram.

Com a aprovação desta Portaria aumentou-se a efetividade das ações em saúde para a população em situação de rua, a considerar que era necessária uma boa interação das redes de saúde de modo a 
oferecer melhores respostas para a referida população. O CnaR passou então a ter como suporte para atendimento dessa demanda além de outras UBSs, hospitais públicos da cidade, CAPSs entre outros, com o objetivo de realizar consultas, exames laboratoriais e demais procedimentos ambulatoriais necessários $^{(1)}$.

Neste contexto, a população em situação de rua requer que os profissionais de saúde instituam linhas de cuidados que atendam suas necessidades, indiscutivelmente inconstantes no que se refere à adesão ao tratamento e condutas relacionadas à promoção da saúde e prevenção de doenças ${ }^{(5)}$. Para tanto, é notória a necessidade de criação de vínculo entre os profissionais de saúde e os indivíduos, identificando os agravos, e possíveis danos, que norteiam o trabalho da equipe com esse público ${ }^{(6)}$.

Considerando o exposto, o objetivo deste estudo foi conhecer as percepções dos pacientes sobre o atendimento oferecido pela equipe multiprofissional aos usuários atendidos pelo programa Consultório na Rua do município de Imperatriz - MA.

\section{MÉTODOS}

Trata-se de uma pesquisa exploratória descritiva com abordagem qualitativa ${ }^{(7-9)}$.

O local de estudo foi o CnaR do município de Imperatriz - MA, vinculado a Atenção Básica, que tem como sede a UBS Três Poderes. A pesquisa ocorreu durante o
A população desse estudo foram pessoas atendidas pelo CnaR, abordados durante seus atendimentos pela equipe multiprofissional. Segundo os profissionais da equipe existe cerca de 200 pessoas em situação de rua que são atendidas. Foram incluídos pacientes atendidos e cadastrados no programa CnaR. Excluiu-se do estudo aqueles que abandonaram/não realizaram nenhum atendimento há mais de 12 meses e/ou que tivessem alguma condição patológica que impossibilitasse a coleta de dados.

Desta forma, a amostra final foi composta por 16 participantes, suficiente para atender a saturação dos dados de modo que não houve nenhum novo elemento encontrado e o acréscimo de novas informações ${ }^{(10)}$.

Os dados foram coletados através de entrevista semiestruturada, usando um roteiro pré- estabelecido que iniciou com a pergunta: Qual o motivo da sua busca pelo atendimento no Consultório na Rua? Por que você procurou este serviço? Desde quando você foi atendido aqui? Se não é sua primeira vez, por que voltou/volta? Despois se seguiram outras perguntas.

As entrevistas foram gravadas e realizadas pelos pesquisadores, e posteriormente transcritas e aconteceram de forma individual, em local reservado durante os horários de atendimento, e o espaço para a realização da entrevista ficou a critério de cada entrevistado, sendo a UBS ou o abrigo ou mesmo o veículo que transportava a equipe mês de Maio de 2019. 
do CnaR, desde que o entrevistado concordasse.

Os dados foram analisados empregando o método de análise de conteúdo em três fases: descrição, análise, interpretação ${ }^{(8)}$ tendo como auxílio o software Atlas.ti(11). Em síntese este processo se materializou pela inserção das entrevistas transcritas, seleção de trechos de citações com associação a um ou mais códigos, e agrupamento dos códigos a três grupos de códigos, chamados de categorias. São elas: Motivos e frequência dos atendimentos; Acolhimento e satisfação dos usuários; Expectativas frente aos serviços ofertados.

O estudo atendeu todos os preceitos éticos previstos na resolução $n^{\circ} 466 / 12$ do Conselho Nacional de Saúde e foi aprovada pelo Comitê de Ética em Pesquisa da Universidade Federal do Maranhão sob parecer número 3.053 .779 emitido em 03/12/2018. Com vistas a garantia do anonimato os participantes foram identificados no estudo com nomes fictícios de deuses gregos (Afrodite, Apolo, Ares, Ártemis, Atenas, Deméter, Dionísio, Eros, Hades, Hélios, Hermes, Horas, Poseidon, Selene, Têmis, Zeus).

\section{RESULTADOS}

No tocante às características sociodemográficas, dos 16 participantes do estudo, tinham idade que variava de 20 a 65 anos, todos eram do sexo masculino. Quanto ao estado civil, um era casado, seis eram https://doi.org/10.31011/reaid-2021-v.95-n.34-art.1024 Rev Enferm Atual In Derme v. 95, n. 34, 2021 e-021075 solteiros, sete divorciados e dois viviam em união estável. Residiam em abrigos 10 participantes e seis na Associação de Proteção e Assistência aos Condenados (APAC). Um não tinha instrução, nove tinham Ensino Fundamental incompleto, dois Ensino Fundamental completo e quatro Ensino Médio incompleto. No que tange às ocupações, três afirmaram ter algum tipo de trabalho, dois eram pedintes, sete desempregados, um recebia auxílio reclusão e um não informou. Quanto à raça/etnia, um informou ser branco, 13 pardos e dois negros.

\section{Motivos e frequência dos atendimentos}

Os sujeitos em seus relatos iniciaram expressando os motivos pelos quais procuraram os serviços oferecidos pelo CnaR, o que evidenciou tanto a necessidade dessas pessoas como as ações de busca ativa realizada pela equipe multiprofissional, como segue nas falas:

\footnotetext{
"Por que eles vêm aqui e eu gosto de saber da minha saúde".

(Selene)

"Por causa da fraqueza, dor nas pernas a anemia que sempre tenho, queria saber se melhorei". (Afrodite)

"Eu não busquei eles não sabe! Eles que são preocupados com a saúde das pessoas e vem procurar a gente, só pessoas com Deus no coração faz isso sabe! Mas eu estava sentido dor nas costas". (Hades)
} 
"Pra resolver a necessidade de saúde que a gente tem e por que aqui no abrigo eles sempre vêm fazer $\mathrm{o}$ atendimento aqui. $\mathrm{E}$ eu consulto quando preciso". (Apolo)

"Eu fique sabendo que tinha um povo da saúde que ajudava as pessoas e eu precisava de passagem e estava morando na rua, daí a assistente social que me trouxe para este lugar e aqui, eu tive lugar pra dormir, comida, roupa limpa e consultas com a doutora". (Zeus)

Quanto à percepção sobre os atendimentos recebidos e da frequência destes, a considerar qualidade e retorno, os sujeitos relataram em suas falas uma boa avaliação, ao mesmo tempo em que afirmaram ser incipiente o número de atendimentos, como descrito abaixo:

"Eu gostei muito me ajudou quando ninguém queria saber, a vida na rua é muito ruim, você é só! Eu ficava sozinho, tinha medo, não sabia o que podia acontecer se eu ficasse doente". (Poseidon)

"Achei muito bom o atendimento, as pessoas são atenciosas, educadas e não tem nojo da gente e tem medo o que acontece em muitos lugares onde andamos isso tudo só por causa da nossa roupa suja". (Horas)

"Eu achei muito bom”. (Hades)

"O atendimentos era ótimo, eles nos deixavam a vontade pra ser atendidos! Bem legal". (Apolo)
"Faz tempo, voltei por que eles são preocupados em atender pessoas que moram na rua e me sinto muito bem aqui, sabe, sempre vou voltar". (Deméter)

"Tem uns dois anos, volto porque no posto é muito difícil e as pessoas que nos atendem, não gostam de mim, que eu vá lá, pensam que só por que estou na rua, e sujo sou um ladrão". (Atenas)

"Não sei te falar, mais ou menos uns seis meses que eles não vêm aqui, mas antes eles vinham até duas vezes no mês, mas parou, e tem esse tempo todo que não tenho atendimento". (Apolo)

"Faz tempo, não lembro acho que seis meses. Eles que vinham aqui". (Eros)

\section{Acolhimento e satisfação dos usuários}

O acolhimento recebido pelos usuários foi mencionado em suas falas e demonstrou satisfação, como segue:

"Considero ótimo! Somos pessoas diferentes, muitas pessoas nunca iam querer cuidar da gente, e o grupo do consultório vem e nos ajuda com muito amor, às vezes não tem remédio e eles conversam e nos ensinam como ir buscar ou depois a moça que trabalha ai vem deixar, onde se acha isso? Só de quem trabalha com amor". (Deméter)

"Eu os considero, muito bons, eles atendem a pessoa bem, todos são tratados iguais". (Hélios)

"Eu não sei nem responder essa questão por que ninguém nunca me tratou tão bem, a médica mesmo muito jovem, mas muito educada e preocupada olhou nos 
meus olhos eu senti tanta atenção quando ela me atendeu me deu conselhos, ela é muito bondosa e apesar de ser nova eu sei que ela estudou muito pois ela descobriu tudo do meu problema". (Hades)

"Eles são ótimos, solidários e prestativos, trabalham na normalidade". (Dionísio)

"Muito bem acolhido! Inclusive me deram medicamento na hora eles já tinham e a enfermeira conversou comigo". (Apolo)

"Fui muito bem tratado por eles, pela boa educação que todos tem, eles chegaram perto sem medo, parece que somos iguais, as pessoas tem medo de mim, acham que vou roubar. Eu não sou ladrão! Sou uma pessoa que precisa de trabalho, ainda não consegui! acho que vou arrumar logo, minha família não me quer, e essas pessoas vem me ajudar! agora tudo vai dar certo". (Hades)

"Sim muito acolhido". (Têmis)

"Me sinto sim, acolhido por todos"! (Hermes)

"Muito bem acolhido sabe! Eles conversaram comigo, me dando atenção e explicando como eu ia fazer as coisas, para conseguir o que estamos precisando, o que a gente não vê por ai, eu notei um interesse em ajudar mesmo". (Ares)

Relacionado às percepções de como reconheceram o grau de solução dos problemas de saúde e a quem ou a que atribuíram o crédito por esta resolubilidade, os sujeitos relataram em suas falas:
"Sinto que meus problemas foram resolvidos sim, pois já tenho o remédio, e ela me ensinou como usar. Agora só depende de mim usar direito né"? (Selene)

"Tive solução! A médica muito boa me passou um exame para ver se preciso controlar a pressão". (Artêmis)

"Sim, meus problemas foram resolvidos! eu estava doente com uma dor e a doutora me consultou a enfermeira me deu remédio, hoje sou grato e sei que tem pessoas boas e as pessoas de rua podem ficar doentes que eles vêm aqui e olham pras pessoas como eu, que não tem ninguém. Aqui eles se preocupam mandam a gente tomar vacina e tudo. Eu dou muito credito a todos eles, pois minha vida esta melhor". (Poseidon)

"Sim, resolvem! Hoje eu tenho um lugar como esse aqui bom! Pra quem vive na rua, a vida é muito ruim, sabe! Fiquei bom da coceira tenho um lugar para morar e só está faltando a passagem, mas a assistente social vai me ajudar, agradeço a todos". (Zeus)

Os sujeitos relataram ainda suas experiências pregressas nos atendimentos. Observou-se que os mesmos apresentaram-se satisfeitos com os atendimentos, mas relataram ações/situações que minimizaram a qualidade dos serviços ofertados, como segue em suas falas:

"Muito satisfeito, todos foram muitos educados e me ajudaram. Agora eles deviam ficar mais atentos ao pessoal que fuma 
droga, às vezes tem uns caras que fumam escondidos". (Eros)

"É tudo bom, não tenho o que falar não, o atendimento não, é ruim não, estou muito satisfeito, só que eles demoram vim aqui queria que eles viessem mais vezes". (Poseidon)

"Está ótimo, eles têm tudo. Aqui é minha casa agora e tem pessoas que vem cuidar de mim”! (Zeus)

"Muito satisfeito! Agora eu tomo os remédios pra os meus problemas, entendeu! Só acho que eles deveriam vir mais aqui! Eles demoraram muito". (Têmis)

"Gostei muito do atendimento, só achei corrido o tempo, tinha muita gente para atender, mas espero ter uma saúde melhor agora". (Artêmis)

\section{Expectativas frente aos serviços ofertados}

Os sujeitos expuseram suas considerações no que se refere ao que esperavam, considerando seus desejos/expectativas para com a assistência de saúde recebida da equipe multiprofissional, novamente enfatizaram a importância da assistência prestada e a satisfação com esta, como segue em suas falas:

"Eu espero que sempre melhore, sabe! Mas é bom, mas quanto mais eles melhorarem, é melhor! Mas o atendimento é ótimo" (Eros)

"Que eles continuem distribuindo um trabalho como este, para ajudar muitas pessoas como a gente, sabe! As coisas não são fáceis pra gente não, e nem todos querem saber de ser bom! Ser solidário"! (Ares)

"Eu espero que continuem! Sabe, antes era muito difícil e agora está mais fácil consultar e tomar os remédios. Eu tenho mais saúde agora". (Deméter)

"Eles fazem tudo do alcance deles, mas talvez possa melhorar por que o ser humano sempre quer mais". (Zeus)

\section{DISCUSSÃO}

Perfil sociodemográfico com algumas semelhanças foi encontrado em estudo realizado em Manguinhos (RJ) onde 61\% dos participantes eram homens, 33\% pardos ou negros e, $96 \%$ usavam algum tipo de $\operatorname{droga} a^{(12)}$.

Pesquisa realizada em Maceió-AL ${ }^{(13)}$ mostra resultados semelhantes, onde os participantes evidenciaram a importância da equipe do CnaR para a saúde deles como se observa nas falas: "Deus que enviou vocês, pra vir salvar a gente dessa vida". (E3) "Eles tratam a gente como se a gente fosse única" (E7)

A assistência em saúde oferecida pelo CnaR tem um vasto campo de atuação e direciona-se em acolher essa população com demandas tão diversas e complexas, descentralizando suas ações no intuito de não focar somente em ações curativas, mas expandindo suas atividades na promoção em saúde e boas práticas com intuito de resgatar a qualidade de vida dos usuários ${ }^{(6)}$. 
É de fundamental importância a realização da busca ativa efetiva, tendo em vista que o reconhecimento das especificidades nos processos de cuidado e a interação com o campo de atuação (território geográfico e simbólico) constituem um desafio para o desenvolvimento do trabalho da equipe multiprofissional, adaptado às novas práticas em saúde ${ }^{(14)}$.

Nesta perspectiva, é possível ratificar a importância e a possibilidade da prestação de serviços de qualidade pelo CnaR, a considerar que em estudo realizado em uma capital do nordeste brasileiro foi possível observar ações não limitadas ao curativo e promovendo/oferecendo também suporte psicossocial no intento dos atendimentos transcenderam o biológico e trazer mudanças para a população ${ }^{(13)}$. Os autores destacam ainda que os usuários lutam contra as dificuldades para ter acesso a serviços públicos aliados a discriminação/preconceitos por parte de profissionais das Redes de Atenção à Saúde, o que tem prejudicado o manejo clínico desses usuários.

Considerando a ótica exposta, foi notório que a frequência de atendimento relatada nas falas dos participantes destoa do preconizado na Portaria $n^{\circ} 122 / 2011$ do Ministério da Saúde que trata das equipes do CnaR, onde se estabelece uma carga horária semanal de 30 horas $^{(1)}$ para os profissionais da equipe, o que não foi observado pelos pesquisadores, sendo justificado como falta de insumos e dificuldades na logística como falta de veículo para transportar a equipe, o que dificulta o atendimento dos usuários de forma adequada.

Estudo realizado em Manguinhos no Rio de Janeiro mostrou que os profissionais do CnaR são fundamentais para acolher as pessoas em situação de rua incluindo-os nos serviços de saúde, sempre considerando-se sua extrema vulnerabilidade ${ }^{(12)}$.

O acolhimento é uma das etapas do atendimento mais importantes, que envolve escuta ativa sem juízo de valores ou preconceitos, e desta forma, emerge a necessidade de trabalhar com os usuários as possibilidades de cuidado, respeitando os limites e possibilidades individuais ${ }^{(13-15)}$.

Desse modo, em termos de resolubilidade, é primordial que as ações estejam alinhadas não somente na utilização de recursos instrumentais e conhecimento técnico pelos profissionais, mas aliar ação acolhedora no intuito de estabelecer relações de vínculo com os usuários, construindo uma relação profissional/usuário ${ }^{(16)}$.

A partir destes relatos, infere-se que os sujeitos da pesquisa, apresentaram um grau alto de satisfação com os serviços ofertados, e reconheceram o trabalho da equipe multiprofissional como um todo. Salienta-se, no entanto, que segundo o Ministério da Saúde o CnaR não é a única porta de entrada da população em situação de rua no SUS, podendo o acesso ocorrer também por meio da UBS e pelas Unidades de Pronto Atendimento (UPA) ${ }^{(12)}$. 
O êxito do CnaR tem substancial participação da competência e insistência dos profissionais em construir formas de cuidar, por vezes transpassando barreiras institucionais do sistema de saúde e deficiências da articulação setorial entre as políticas públicas ${ }^{(14)}$.

A frequência de atendimentos é um fator que compromete a qualidade no serviço, sendo esta deficiência na periodicidade dos atendimentos percebida pelos usuários. Cabe ressaltar que no momento da pesquisa $o$ programa passava por conflitos gerenciais de caráter logístico e operacional.

Para tanto se observou que um dos grandes óbices vividos pela população em situação de rua eram os entraves para conseguir atendimento, e quando conseguiam, nem sempre usufruíam de cuidado de qualidade e continuidade deste atendimento $^{(17)}$.

Neste sentido, o CnaR configura-se como excelente e ao mesmo tempo desafiante estratégia em saúde, a saber, que em suas atividades/ações consegue abrir brechas nas endurecidas estruturas da saúde e de outras políticas sociais brasileiras, para que todos, sem exceção, possam usufruir dos serviços de saúde ${ }^{(2)}$.

A população atendida pelo $\mathrm{CnaR}$ carece de uma melhor assistência e de cuidado em saúde, tornando necessários serviços mais articulados, possibilitando e garantindo a atenção integral e equânime aos usuários $^{(4)}$.
Atos como solicitar exames e prescrever medicamentos não devem limitar a atuação dos profissionais da equipe do CnaR, devendo eles estar também aptos e abertos ao diálogo com os usuários ${ }^{(16)}$, considerando as suas histórias, seus desejos e angústias, que são partes fundamentais de seus projetos de vida, perfazendo desta forma o rompimento da proposição fragmentada do atendimento que não considera amplamente todos os aspectos envolvidos no adoecimento.

Assim, a existência de particularidades presentes tanto nos processos que envolvem o adoecimento, como os subsequentes processos de cuidado aos usuários do $\mathrm{CnaR}$ e a adesão aos serviços ofertados ${ }^{(18)}$. Tais processos incluem questões ligadas à própria organização do serviço, a citar: exigência de documentação, limites na atuação intersetorial, preconceitos, restrição nos atendimentos entre outras, que possam fomentar a criação de vínculos precários ${ }^{(19)}$.

$\mathrm{O}$ atendimento a pessoas em situação de rua deve ser pensado por profissionais da saúde sem preconceito e estigmatização já que essas pessoas vivem em situação de extrema vulnerabilidade e exclusão social.

\section{CONCLUSÃO}

Os resultados do estudo demonstraram que os usuários do CnaR eram homens pardos, divorciados, com idade entre 20 a 35 anos, residiam em abrigos, cursaram ensino fundamental, estavam desempregados. A estratégia do CnaR foi avaliada de forma 
positiva pelos usuários e a limitação apresentada foi a falta de insumos e logística que carecia a equipe. O compromisso da equipe e os entraves administrativos foram mencionados, assim como o acolhimento presente (com o uso da escuta qualificada) entre os usuários, fator que fortalecia o vínculo entre equipe/paciente. Os usuários expressaram satisfação com os serviços ofertados pela equipe.

Constatou-se a importância do CnaR como ferramenta que possibilita ampliar a oferta de atenção integral à saúde para a população de rua e, por meio das equipes e serviços de assistência a saúde, oferecer uma assistência integral dentro da realidade $\mathrm{e}$ individualidade de cada pessoa atendida.

Como limitação para a realização do presente estudo pode-se citar a precariedade de insumos e recursos adequados para atender a essa população, bem como a falta de documentação civil das pessoas atendidas o que dificulta seu acesso aos serviços de saúde, além da rotatividade dos locais de permanência das pessoas em situação de rua. As contribuições para a enfermagem são originais e importantes já que permitiu compreender algumas nuances da assistência a usuários que vivem em um cenário complexo e dinâmico.

$\mathrm{O}$ estudo contribuiu para incremento de conhecimentos na temática, além de possibilitar ampliar as percepções sobre a realidade pesquisada. É relevante, pois a compreensão do ponto de vista dos usuários permite avaliar a qualidade do serviço prestado, propiciando capacitação contínua aos profissionais e melhoria no atendimento, além de contribuir para novas pesquisas.

\section{Agradecimentos}

Este estudo foi financiado pela Coordenação de Aperfeiçoamento de Pessoal de Nível Superior - Brasil (CAPES) - Finance Code 001 .

\section{REFERÊNCIAS}

1. Brasil. Ministério da Saúde. Portaria $n^{\circ}$ 122, de 25 de janeiro de 2011. Define as diretrizes de organização e financiamento das Equipes de Consultório na Rua. Brasília (DF): Presidência da República; 2011. [acesso em 2020 Jun 10]; Disponível em: http://bvsms.saude.gov.br/bvs/saudelegis/ gm/2012/prt0122_25_01_2012.html

2. Abreu D, Oliveira WF. Atenção à saúde da população em situação de rua: um desafio para o Consultório na Rua e para o Sistema Único de Saúde. Cad. Saúde Pública [Internet]. 2017 [acesso em 2019 Jun13]; 33(2):e00196916. Disponivel em: http://www.scielo.br/pdf/csp/v33n2/16784464-csp-33-02-e00196916.pdf/.

3. Rocha MSB. Nuances do consultório na rua (dissertação). Goiânia- GO: Instituto de Patologia Tropical e Saúde Coletiva (Profissional); 2016.

4. Alecrim TFA, Mitano F, Reis AA, Roos CM, Palha PF, Protti-Zanatta ST. 
Experiência dos profissionais de saúde no cuidado da pessoa com tuberculose em situação de rua. Rev. esc. enferm. USP [Internet]. 2016 [acesso em 2019 Jun 08];50(5):808-15. Disponível em: http://www.scielo.br/scielo.php?script=sci _arttext\&pid=S0080$62342016000500808 \& \operatorname{lng}=$ pt.

5. Gomes DF, Elias FTS. Políticas publicas de assistência social para população em situação de rua: analise documental. Com. Ciências Saúde [Internet]. 2016 [acesso em 2019 Jun 15]; 27(2):151-8. Disponível em:

https://repositorio.ufsc.br/handle/1234567 $89 / 133025$.

6. Machado KS, Simas RS. Redução de danos, insumos e experiência estética: uma análise da prática no Consultório na Rua do município do Rio de Janeiro. Rev. Interinst. Bras. Ter. Ocup. [Internet]. 2017[acesso em 2021 Abr 22]; 1(1):6783. Disponível em:

DOI: 104777/2526-3544.rbto4823

7. Yin RK. Pesquisa qualitativa do início ao fim. Porto Alegre (RS): Editora Penso; 2016.

8. Deslandes SF. Pesquisa social: teoria, método e criatividade. Petrópolis (RJ): Editora Vozes; 2016.

9. Silva $\mathrm{R}$ et al. Estudos qualitativos: enfoques teóricos e técnicas de coleta de informações. (Orgs). Sobral: Edições UVA; 2018.
10. Nascimento LCN, Souza TV de, Oliveira ICS, Moraes JRMM de, Aguiar RCB de, Silva LF da. Theoretical saturation in qualitative research: an experience report in interview with schoolchildren. Rev. Bras. Enferm. [Internet]. 2018 [acesso em 2020 Jul 10]; 71(1):228-33. Disponível em: http://dx.doi.org/10.1590/0034-71672016-0616

11. Friese S, Soratto J, Pires D. Carrying out a computer-aided thematic content analysis with ATLAS.ti. MMG Working Paper [Internet]. 2018 [acesso em 2019 Fev 09]; 18(2):1-30. Disponível em: https://pure.mpg.de/rest/items/item_25829 14_2/component/file_2582912/content.

12. Silva CC, Cruz MM, Vargas EP. Práticas de cuidado e população em situação de rua: o caso do Consultório na Rua. Saúde debate [Internet]. 2015 [acesso em 2019 Jun 10]; 39( pe): 246-56. Disponível em: http://www.scielo.br/scielo.php?script=sci _arttext\&pid=S0103$11042015000500246 \& \operatorname{lng}=$ en. http://dx.doi.org/10.5935/01031104.2015S005270.

13. Ferreira CPS, Rozendo CA, Melo GB. Consultório na Rua em uma capital do Nordeste brasileiro: o olhar de pessoas em situação de vulnerabilidade social. Cad. Saúde Pública [Internet] 2016. [acesso em 2020 Ago 06]; 32(8):e00070515. Disponível em: https://www.scielo.br/pdf/csp/v32n8/1678 -4464-csp-32-08-e00070515.pdf 
14. Rosa AS, Santana CLA. Consultório na Rua como boa prática em Saúde Coletiva. Rev. Bras. Enferm. [Internet]. 2018 [acesso em 2019 Jun 03]; 71( Suppl 1): 465-6. Disponível em: http://www.scielo.br/scielo.php?script=sci _arttext\&pid=S0034$71672018000700465 \& \operatorname{lng}=$ en.

15. Santos EM, Campos CJV, Reis HFT, Reis Junior WM, Louzado JÁ, Silva GR. Representações sociais do cuidado de enfermagem em saúde mental na atenção básica. Rev Enferm. Atual in derme [Internet] 2019. [acesso em 2021 Abr 22]; $87: 1-8$. Disponível

em: https://revistaenfermagematual.com/index .php/revista/article/view/154/60

16. Teixeira M, Fonseca Z. Saberes e práticas na atenção primária à saúde: cuidado à população em situação de rua e usuários de álcool, crack e outras drogas. 1. ed. São Paulo: Hucitec; 2015.

17. Brasil. Ministério da Saúde. Secretaria de Atenção à Saúde. Manual Sobre o cuidado á saúde junto à população de rua: políticas complementares do SUS. Brasília (DF): MS; 2014. [Acesso em 2019 Mai 20]; Disponível em: http://bvsms.saude.gov.br/bvs/publicacoes /saude_populacao_situacao_rua.pdf.

18. Louzada LO. Análise das práticas das primeiras equipes de consultório na rua do munícipio do Rio de Janeiro: caminhos para o exercício da clínica ampliada na perspectiva dos profissionais. [dissertação] Rio de Janeiro - RJ: Escola Nacional de Saúde Pública Sergio Arouca; 2015.

19. Paiva IKS, Lira CDG, Justino JMR et al. Direito à saúde da população em situação de rua: reflexões sobre a problemática. Ciênc. saúde coletiva [Internet]. 2016 [acesso em 2019 Jun 12]; 21(8): 2595606. Disponível em: http://www.scielo.br/scielo.php?script=sci _arttext\&pid=S1413$81232016000802595 \& \operatorname{lng}=\mathrm{en}$. http://dx.doi.org/10.1590/141381232015218.06892015.

Submissão: 2021-02-14

Aprovado: 2021-05-14 